\title{
Laments and Relational Personhood: Case studies from Duna and Awiakay societies of Papua New Guinea
}

\author{
Kirsty Gillespie and Darja Hoenigman
}

Lamenting is a very important aspect of musical culture across Papua New Guinea, a country of more than 800 indigenous language groups and a vast variety of cultural practices. ${ }^{1}$ Many anthropological texts address the lament across the country. ${ }^{2}$ In Papua New Guinea, laments - which we define for our purposes as verbal expressions that are performed at the death of a person or other living being (as opposed to verbal expressions about loss more generally)are established genres that usually have a name or category attached to them. Although lamenting is typically the domain of women, and older women in particular, who bring to the genre a great body of knowledge and considerable skill accumulated over years of mourning, both adult men and women can be composers and performers of laments, particularly in Awiakay society. Laments in Papua New Guinea can be microcosms of a culture; they contain within them much detail about the life of the deceased, and the lamenter, listing the places of their heritage, the activities they once performed and their role within the community, as well as pointing to any existing tensions in relationships between the lamenter and other members of the community, and thus aiming at socially appropriate actions that need to be taken in order to re-establish distorted relationships. Laments are thus as much a part of the present (and consequently the future) as they are of the past. Therefore, to examine a lament closely is to learn much about Papua New Guinean cultures.

\footnotetext{
1 This chapter is based on two individual papers presented by the authors at the round table of the Laments Colloquium organised by the International Council for Traditional Music and the School of Music, The Australian National University. We would like to thank the organisers for inviting us to participate at the colloquium, and Andrew Pawley, Alan Rumsey and Aung Si for their helpful comments on earlier drafts of this paper. In addition, Gillespie wishes to thank the Duna people with whom she has worked for allowing her to record and study laments with them, and also Lila San Roque for ongoing linguistic advice. Hoenigman would like to acknowledge Pip Deveson, Gary Kildea and Robert Nugent for their inspiration, advice and help with editing and subtitling the film about Kununda's lament, the excerpt of which accompanies this chapter. Hoenigman's warmest appreciation goes to Awiakay people, and in particular to her late adoptive mother, Susi Kununda, for letting her record the lament discussed in this paper and teaching her proper Awiakay ways until the end of her days.

2 See, for example, Schieffelin, Edward L. 1976, The Sorrow of the Lonely and the Burning of the Dancers, St Martin's Press, New York; Feld, Steven 1982, Sound and Sentiment: Birds, weeping, sound and poetics in Kaluli expression, University of Pennsylvania Press, Philadelphia; Weiner, James F. 1991, The Empty Place: Poetry, space and being among the Foi of Papua New Guinea, Indiana University Press, Bloomington and Indianapolis.
} 


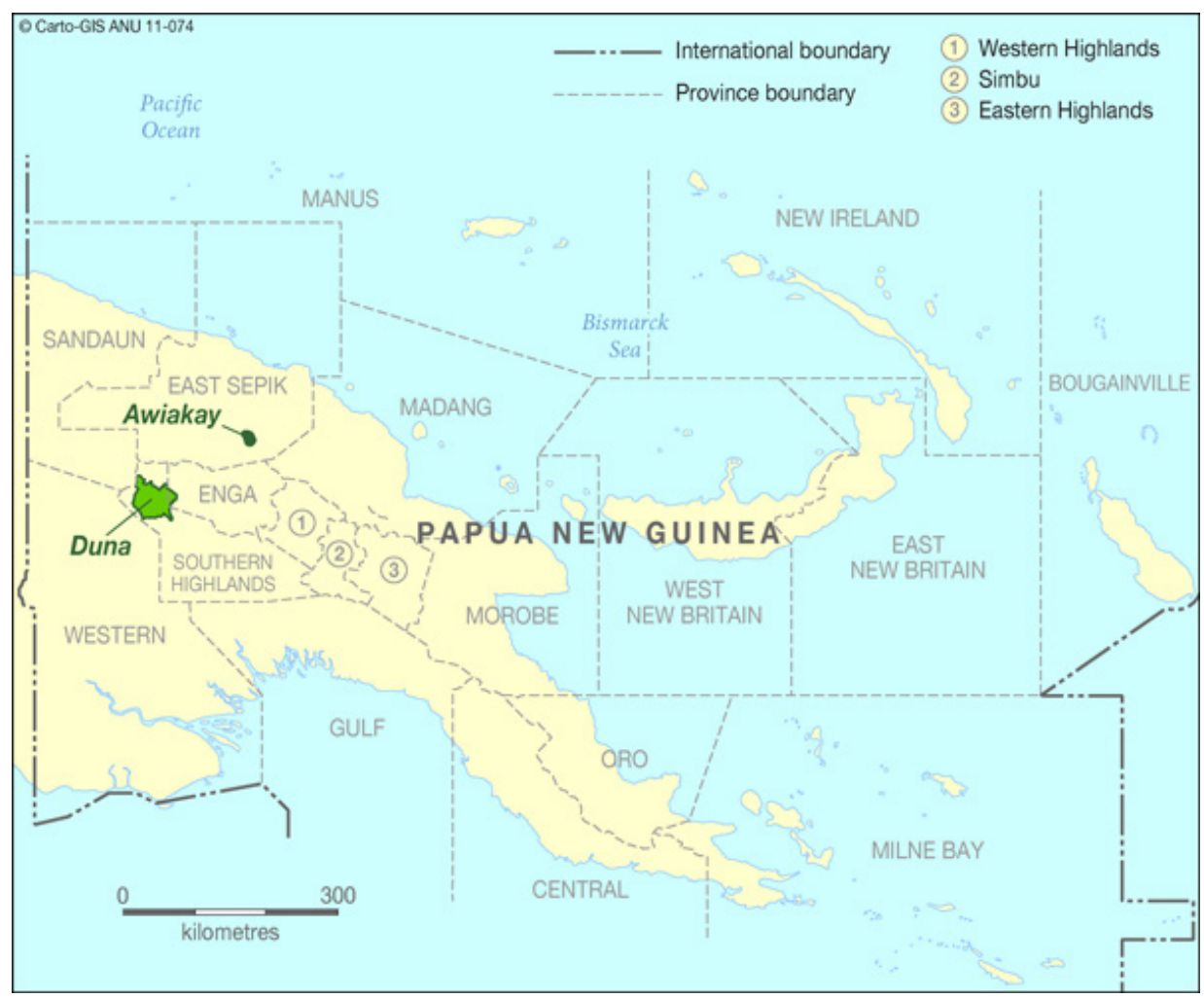

Map 1 Map of Papua New Guinea indicating Awiakay and Duna land

Source: Carto-GIS, The Australian National University

In this chapter, we consider laments from two unrelated language groups in Papua New Guinea with which we have worked closely: the Duna of the Southern Highlands Province/Hela region who live around Lake Kopiago (Gillespie), and the Awiakay, a small community of about 300 people living in Kanjimei village in the lowland rainforest of the Sepik southern flood plain in East Sepik Province (Hoenigman). We show examples of people lamenting both for deceased people and for deceased dogs, who are in some Papua New Guinean cultures such as the Awiakay seen as their owners' extensions.

We would like to frame these laments within a discourse of relational personhood as it relates to both cultures. In recent times there has been considerable debate in the field of Melanesian anthropology over the idea of 'personhood' and the 'individual'. There is a strong view held by some scholars against applying a Western notion of the 'individual' to Melanesian societies; these scholars argue that a Melanesian person should instead be considered a 'dividual' - that is, someone who is relationally constituted, someone who is defined largely by their 
relationships with others. ${ }^{3}$ The laments we present today, whilst illustrating the personal or 'individual' loss experienced by the lamenter, show clearly these social relationships and the loss that is experienced by the wider community of which the deceased was a part. As it will be seen in the second case study, these laments can also be used as an expression of existing imbalances in the community and thus be part of the process of righting such perceived wrongs.

\section{Duna Laments}

For the Duna, lamenting so dominates the musical landscape of women's performance that it was thought for a time that there was no other style sung by them worth describing: 'Except for mourning laments and tuneless ditties sung while gardening or walking home in the rain, Duna women do not really sing at all. $^{4}$ While women are the primary performers of laments in Duna culture, some men also sing laments, though usually only when experiencing strong emotions at the death of someone closely related to them, and not in the ritual way that women do. Here we will consider examples of both a Duna woman and a Duna man lamenting, and show how this illustrates the idea of the Melanesian relational person. The two laments, belonging to the general category of khene ipakana ('death songs'), as they are known in the Duna language, represent the spontaneous musical outpourings on the sudden death of the twenty-year-old Duna woman Wakili Akuri, in February 2005, by those close to her.

\section{Kipu's Lament}

Kipu Piero was a close friend of Wakili. Wakili lived with Kipu, her husband, Kenny, and children in their hamlet near Lake Kopiago until a few months before her death, when she had returned to live with her parents. Wakili was like a sister to Kipu (who had only brothers), helping with chores and with looking after Kipu's four children - particularly the youngest, Monika, Kipu's only girl. On the morning of Wakili's death, a very emotional Kipu circled the houses of the hamlet crying for Wakili. The following are single line excerpts from this lament: ${ }^{5}$

\footnotetext{
3 See Strathern, Marilyn 1988, The Gender of the Gift: Problems with women and problems with society in Melanesia, University of California Press, Berkeley.

4 Modjeska, Charles Nicholas 1977, Production among the Duna: aspects of horticultural intensification in central New Guinea, PhD dissertation, The Australian National University, Canberra, p. 332.

5 A full transcript and the associated audio file (named Audio 14) can be found in Gillespie, Kirsty 2010, Steep Slopes: Music and change in the Highlands of Papua New Guinea, ANU E Press, Canberra. <http://epress. anu.edu.au/titles/steep_slopes_citation>, pp. 223-32.
} 


\section{Example 1 Excerpts from Kipu's lament}

aluarena kenaka aru awanana na panenope?

We two care for and cradle the blonde children, now what will I do...

na wara nendeke nangayana na panenope?

I don't do and make friends with other wara women, now what will I do...

Na ayako wanpis na ko kono neyarape...

I'm a lone ayako, weren't you thinking...

warali suni narayania ruwata kenaka aru awanana na panenope?

You said I had no lastborn warali suni sister and we two would care for and cradle (my children), now what will I do...

Monika kampani koneya antia wali-a aki pora antia wali-a

(My daughter) Monika's true companion, mother oh, what have you done? Mother oh...

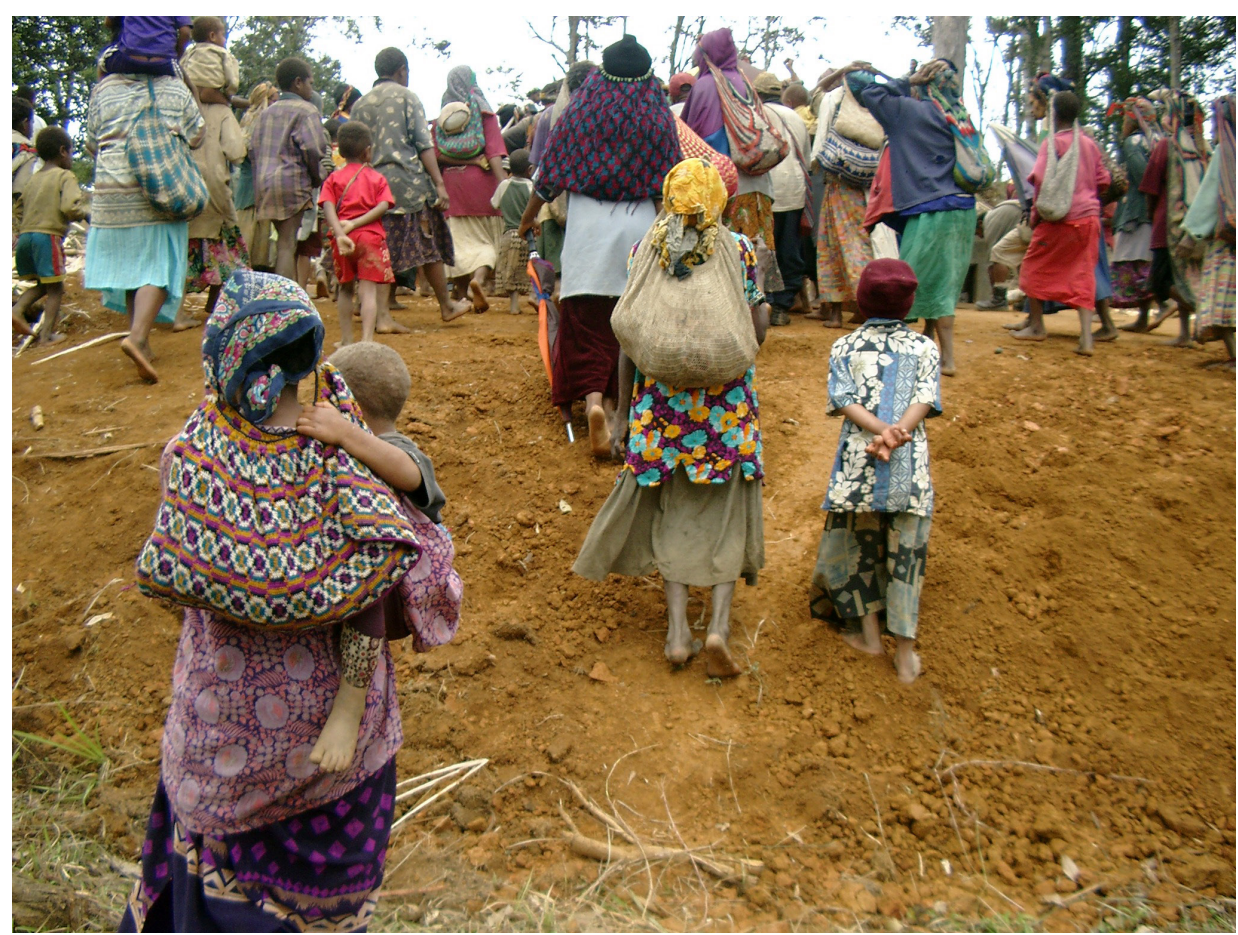

Figure 1 Kipu carries daughter, Monika (in foreground), as they ascend with others to Wakili's gravesite for the burial

Photograph by K. Gillespie 
In her grief, Kipu expresses her own loss but also the hole now made in the family circle, and evokes the responsibilities now unfulfilled. Wakili is depicted as child carer and younger sister figure, providing important companionship to Kipu and her children, in particular Kipu's only daughter, Monika, and now that she has departed, there is no-one to fill this place. Wakili is constituted by these roles and relationships alone in this lament - thus presented as a relational person.

\section{Soti's Lament}

Soti Mbulu was Wakili's maternal uncle, and one of very few men heard to sing at the time of her death. On the day of Wakili's funeral, Soti leant on the roof for the coffin that was being constructed, and, first in his full voice and then falsetto, sang of his own feelings of sorrow at her death, and then of the gardening she used to do, preparing the soil for the planting of sweet potato-a staple food in the Duna diet. One of the most important roles for a female in a Duna community is to produce food, and Wakili's sudden exit from the mortal world means there is a gap in the supply of this labour. It is very clear in Duna songs and Duna culture more generally that food nurtures people and people make relationships, and that a lack of food is symptomatic of unbalanced relationships within the community. ${ }^{6}$ The importance of sharing food will also be shown in the Awiakay case study. The motif of food in this Duna lament is further emphasised in the words with which Soti chooses to express his 'individual' grief, as he describes himself as literally 'eating' sorrow (neya meaning here 'to eat', which Gillespie has translated as 'to stomach'). ${ }^{7}$

\section{Example 2 Excerpt from Soti's lament}

ko ngaya kata papu neya kata ngoyana, antia-o

You go and make me stomach this sorrow, then you leave, mother oh

ko ngaya kata pape neya kata ngoyana, antia-o

You go and make me stomach this pape sorrow, then you leave, mother oh

ko ngaya kata yaraka neya kata ngoyana, antia-o

\footnotetext{
6 See ibid., pp. 134-8.

7 The expression of eating sorrow is also written about in the King James version of the Bible. Psalm 127:2 states: 'It is vain for you to rise up early, to sit up late, to eat the bread of sorrows: for so he giveth his beloved sleep.' The fact that this expression occurs in both endogenous and exogenous settings gives further support to the suggestion that both rupture and continuity can exist in the 'local modernity' of the contemporary Papua New Guinean experience. See Jebens, Holger 2011, 'Beyond globalisation and localisation: denominational pluralism in a Papua New Guinean village', The Asia Pacific Journal of Anthropology, vol. 12, no. 1, pp. 91-110, at p. 92. For further discussion on this lament, see Gillespie, Steep Slopes, pp. 100-3.
} 
You go and make me stomach this yaraka sorrow, then you leave, mother oh

koya laranata ndolu weipe? antia-o

You move the mud, one time will you come back? Mother oh

mopotia laranata ndolu weipe? antia-o

Mopotia sweet potato mounds, move the mud, one time will you come back? Mother oh

yarakatia laranata ndolu weipe? antia-o

Yarakatia sweet potato mounds, move the mud, one time will you come back? Mother oh

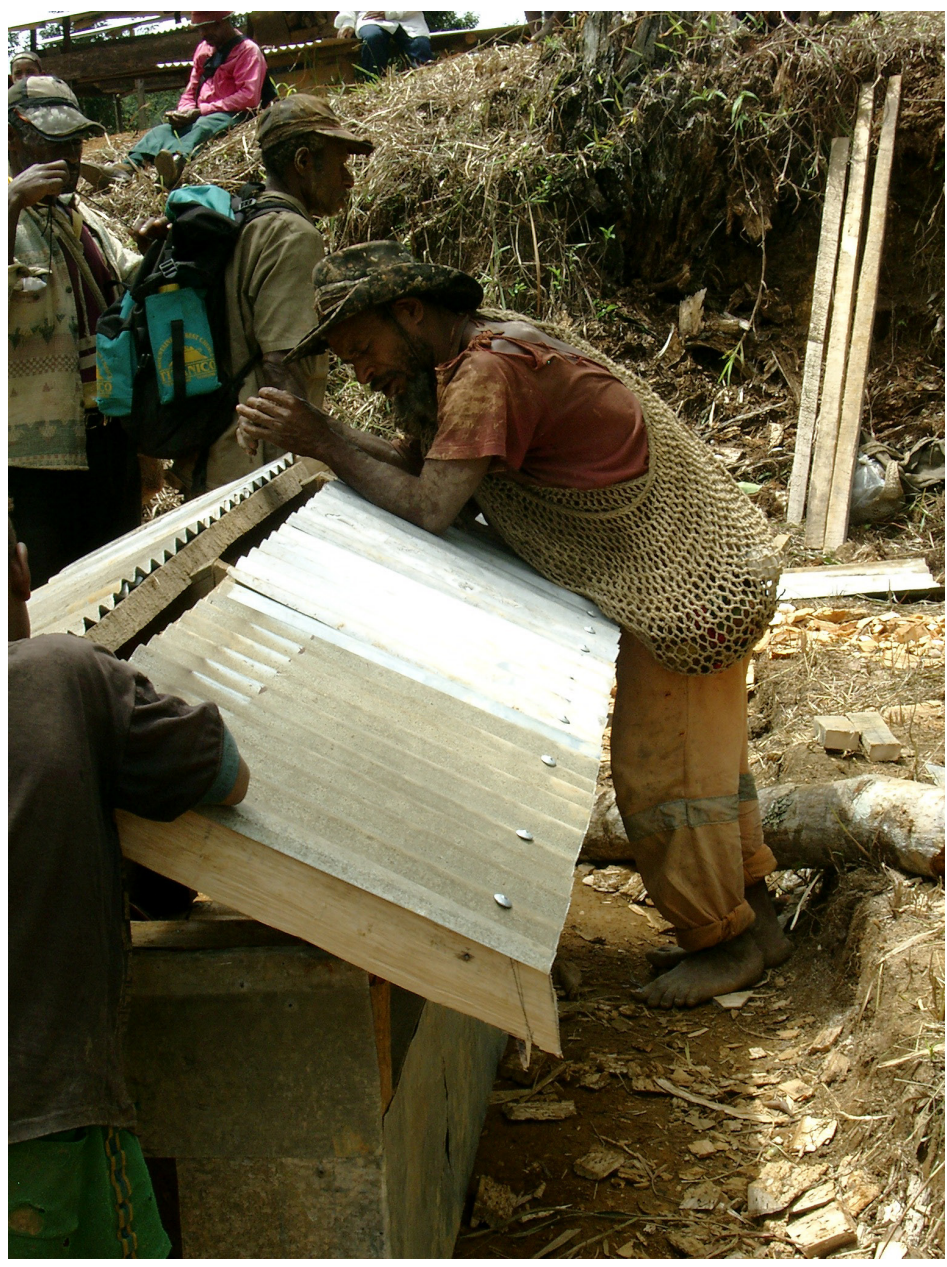

Figure 2 Soti sings against the coffin roof

Photograph by K. Gillespie 
We have characterised the above two laments as 'spontaneous', but it is worth explaining this a little further. By spontaneous we mean in a social sense: these singers have not sat down in the mourning house by the body with the intent to cry, as is the case for many people during this mourning period. Their laments are not primarily driven by an expectation for them to sing at that particular time in order to show their concern and respect, as those less close to the deceased might do, or to assist the deceased's movement into the afterlife, as with the longer repetitive laments that older women in the community might perform. These laments are driven primarily by emotion. They do, however, conform to both musical and textual conventions. Musically these laments are generally made up of descending phrases that start either a third or often a fifth above a tonal centre, and then descend to dwell on the tonal centre for several syllables before ending the phrase with some ornamentation in the form of brief steps either side of the tonal centre. ${ }^{8}$

The text, too, conforms to a particular style, displaying much repetition and word substitution with each repetition. The most valued laments use poetic vocabulary known as kẽiyaka(translated in English as 'praise names' due to the general exalting nature of them) to name places and people. There are several of such kêiyaka for any place or person, and this is how the song form becomes known as khene ipakana yakaya-yakaya meaning to 'name' or 'list' (these special names have been underlined in the above examples). Thus, whilst these very emotional expressions in song are unrehearsed and in a sense unprepared, they are recognised as laments due to their clear adherence to an established set of aesthetic requirements.

\section{Awiakay Laments}

Of the several diverse terms used for this particular genre in English, such as dirge, mourning song, wailing song, funerary chant, wailing and lament, the most suitable gloss for the Awiakay term pukupuku kayapla is Stephen Feld's term 'sung-texted melodic weeping', ${ }^{9}$ because it best describes the practice. Pukupuku can be translated as 'grief', 'worry', 'keeping in thoughts', whereas kayapla is third-person plural present tense for 'cry' (that is, 'they are crying') and functions as the English gerund.

Some of the traditional mourning practices of the Awiakay people, in which the relatives of the deceased would rub their bodies with white clay and stay

8 For a musical transcription of the first minute of Kipu's lament, see Gillespie, Steep Slopes, p. 97.

9 Feld, Sound and Sentiment, p. 93. 
in haus krai (Tok Pisin ${ }^{10}$ term for 'mourning house') for several weeks or even months, ${ }^{11}$ have been abandoned since 1995 when the Catholic charismatic movement, which demanded a radical break with tradition, was brought to the village. This has not had much effect, however, on the composition of melodic texted crying, which accompanies every death.

\section{Weeping for Deceased People}

Crying for a deceased person (first emotional, then hysterical, later melodic and eventually accompanied by text) starts at the moment when people feel the spirit mima has left the body. Oma 'body (of a living person)' thus becomes tundia 'dead body', and mima, which stands for 'a person's spirit, insideness, seat of thoughts, knowledge, mind', turns into tangia, 'the spirit of the dead'. ${ }^{12}$ It stays close to the body and people avoid calling the name of the deceased, as their recently departed spirit could come back and harm them. Instead, they use avoidance terms, such as 'the bald head' or 'the old man' for the oldest, recently deceased man in the village, and so on.

People nowadays cry until just after the funeral; then they encourage each other to stop. ${ }^{13}$ They say that 'worry will destroy a person' and 'sadness will kill life' and they reproach those who are overwhelmed with sadness. Nevertheless, one can occasionally hear melodic weeping coming from the house of the deceased even several months after their death. In the example we discuss here, sungtexted-melodic weeping shows a repeated pattern of alternations between passages of sung text and melodic weeping, organised on three descending pitches, the lowest one always ending with sobbing.

\section{$\underline{\text { SUNG TEXT }}$}

\section{SUNG TEXT continued/MELODIC WEEPING}

\section{MELODIC WEEPING[SOBBING/CRYING]}

It is composed and performed by adult men and women. Although the overall pattern and even some of the phrases are repeated (particularly rhetorical questions aimed at the deceased, asking why they have left without telling anyone, and so on), the content of every lament is unique, depending on the relationship of the deceased and the lamenter. The weeping person usually sings about the places in Awiakay land where the deceased walked, mentions

10 Tok Pisin is an English-based creole, which functions as a lingua franca and is one of the national languages of Papua New Guinea.

11 Hoenigman, Darja 2007, Language and myth in Kanjimei, East Sepik Province, Papua New Guinea, MA thesis, Institutum Studiorum Humanitatis, Ljubljana Graduate School of the Humanities, Ljubljana, pp. 59-62.

12 Compare with: Telban, Borut 2001, Andaypa: Eseji o smrti v novogvinejski skupnosti, Založba Obzorja, Maribor, Slovenia, p. 57. 
their common experiences, grieves over their unfinished work and lists all the good that the deceased did for them, lamenting the fact that there will now be no-one to take care of them. They also bring out their own grievances, which are directed at the living members of the society.

\section{Weeping for Dogs}

As a predominantly hunter-gatherer society, the Awiakay have always had close relationship with their dogs. They appear in a great number of myths. According to one myth, women used to marry dogs who would vomit food for them. One day, one woman discovered a man, and since then dogs have been helping the Awiakay hunt for pigs and cassowaries. In the days when the Awiakay still practised male initiation, one of the most important things that a boy learned during the course of it was how to use hunting magic to make his dog kill many pigs. Apart from people, only dogs and spirit objects have names. Dogs are normally named after powerful spirits. In 2009, of the 83 adult dogs in Kanjimei, 51 had spirit names, seven were named after pain-inflicting plants or animals and 25 dogs carried names borrowed from Tok Pisin, which are also perceived as powerful, as they come from the outside world. Not only among the Awiakay, but also in the wider Sepik area, a puppy is an important gift, which eventually needs to be reciprocated. Dogs are the only mammals that have never been eaten by the Awiakay. Instead, they are fed with sago and treated relatively well. They are only hit or have something thrown at them when they come too close to food or when they fight. A dog becomes an extension of its owner and is in Awiakay belief the only animal that can be, like humans, attacked and killed by a sanguma (Tok Pisin for a kind of a sorcerer, in this area of Papua New Guinea best described as 'assault sorcerer').

Over almost 20 months of fieldwork in Kanjimei, Hoenigman has recorded only one lament for a dog. One of the reasons is that more dogs perish on hunting trips when wounded in a fight with a pig or a cassowary than die of old age. In such a case the dog is buried and cried for in the forest. Their owners' laments are thus never heard by anyone else. Hoenigman was told about two such cases in 2009.

Even when a dog dies in the village, however, this is not an event that would attract much attention, and a dog's burial goes unnoticed by most other people. No matter how important an individual dog is for its owner, it does not have much significance for Awiakay society more generally. 


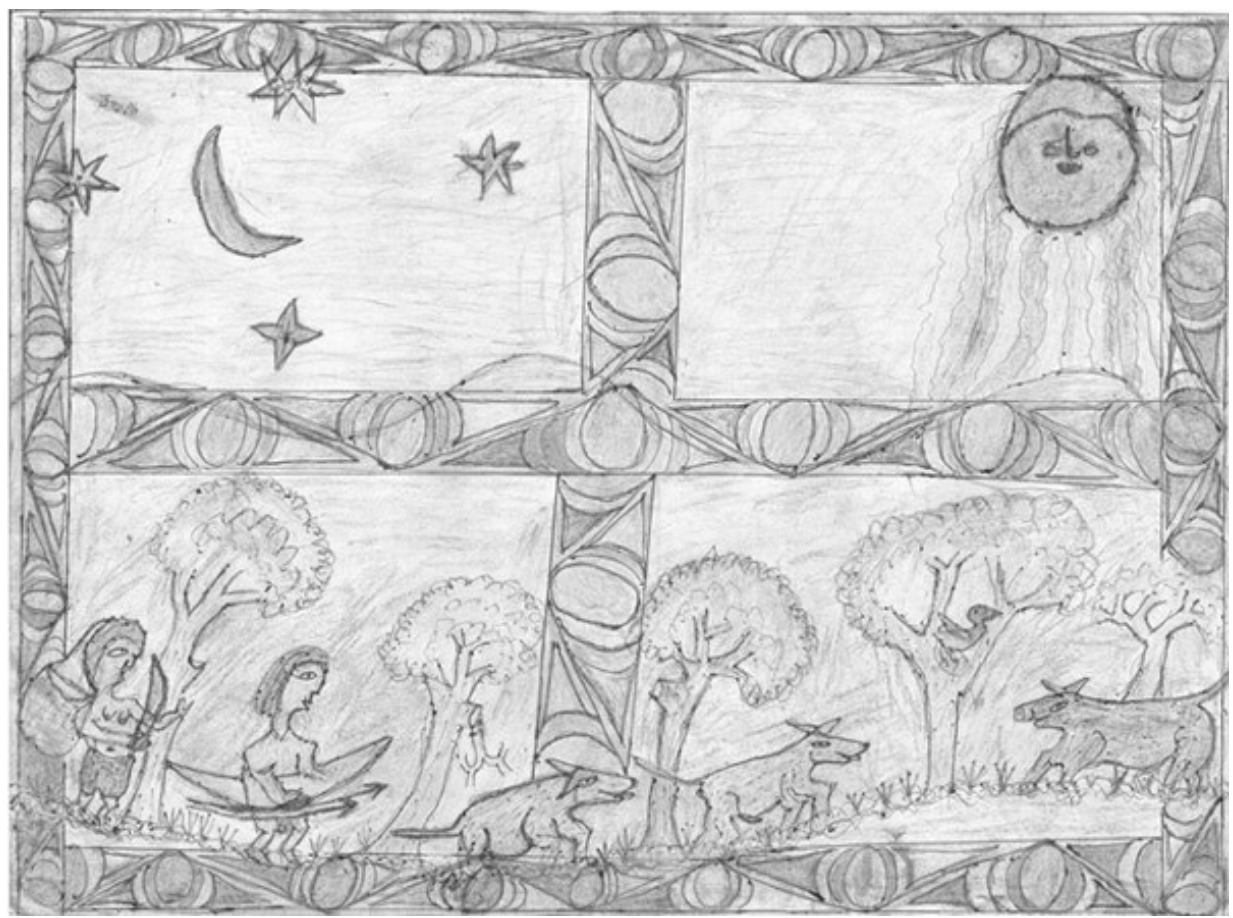

Figure 3 Awiakay man and woman go hunting with dogs

Drawing by Terens Saun, 2004

\section{Kununda's Lament}

One early afternoon in September 2004, Darja's classificatory brother Ingasim came to tell her that Mek had died and was about to be buried. Mek was the dog of Darja's adoptive mother, Kununda, and, as she had seen it hale and hearty the previous day, she rushed to ask her what had happened. She found her quietly crying in the bush behind her house, where her sister Pambain was digging a grave. When the hole was ready, she followed them to the house and saw Mek's body lying next to the wall. Kununda put him onto a leaf sheath, leaned against a post supporting the storage rack above the hearth and started weeping. ${ }^{14}$

14 Transcription conventions followed in Kununda's lament: 1 line numbers, Awiakay text, Tok Pisin, interlinear glosses, [clarification of translation]. 
KUNUNDA:

$1 \quad$ Aunda makangumyame koy aunda nombondimbomiñ.

He was wandering around in the bush and taking care of them, and they just ate it all up [finished all the pigs he killed].

[He was hunting for everyone and they just ate it all.]

Aye...

Ey...

Aunda nombopua, e-e.

They just ate it, e-e.

Aunda nombondimbua, e-e.

They just finished it up, e-e.

5 E-e-e-e...

E-e-e-e.

Usangumbian pepok, e-e...

I tried to tell them, e-e.

Aunda mangombok, aye-e.

I just gave it [the meat of the pigs that the dog had killed] to them, aye-e.

Aunda pokondimbua, e-e.

They just hit him, e-e.

Tungoy tam aka tui nombopokoy, e-e.

I didn't eat my dog's kill secretly by myself, e-e.

10 Tam-o, e-e.

Dog-oh, e-e.

Kambanja kolokotay aka iñipepok e-e.

I didn't hide a little thing [I shared all meat], e-e.

Aunda pokondimbua, e-e.

They just hit him, e-e.

Ambla aka nombopok, papatuy pakaiñasipep, e-e.

I didn't eat it by myself, didn't hide it into a leaf sheath, e-e.

Kay olukunja wambopuakay isomyawakopay opiangombep aka pakainasipok.

When I saw others coming up to the bushcamp I didn't hide it [the meat]. 
Tam-o,e-e.

Dog - oh, e-e.

[Stops crying]

Maninjanda payangombek olukunja opiangombep kopa mangombalik paygombuk aka timbupua.

I saw people [from Konmei who gave me the dog] and I asked them [my sons] for some money to compensate for the debt, but they didn't give me any.

Aunda aygainim yambiay, yambiay, yambiay, ya mengenja aunda pokopep nombopua, aunda mangombok.

I've been walking around in deep worry, while they've been eating the meat [my dog] had killed. I gave it to them for nothing.

Olukunja ison yambakay iskamianjanda aka timbupua.

Those who searched for eaglewood did not give me a bit.

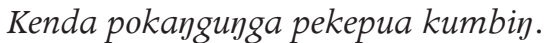

When they came down to the village, they would again hit [the dog].

20 Kenda mengea nombopua, kenda pokangumbua.

They'd eat meat again and they'd hit my dog again.

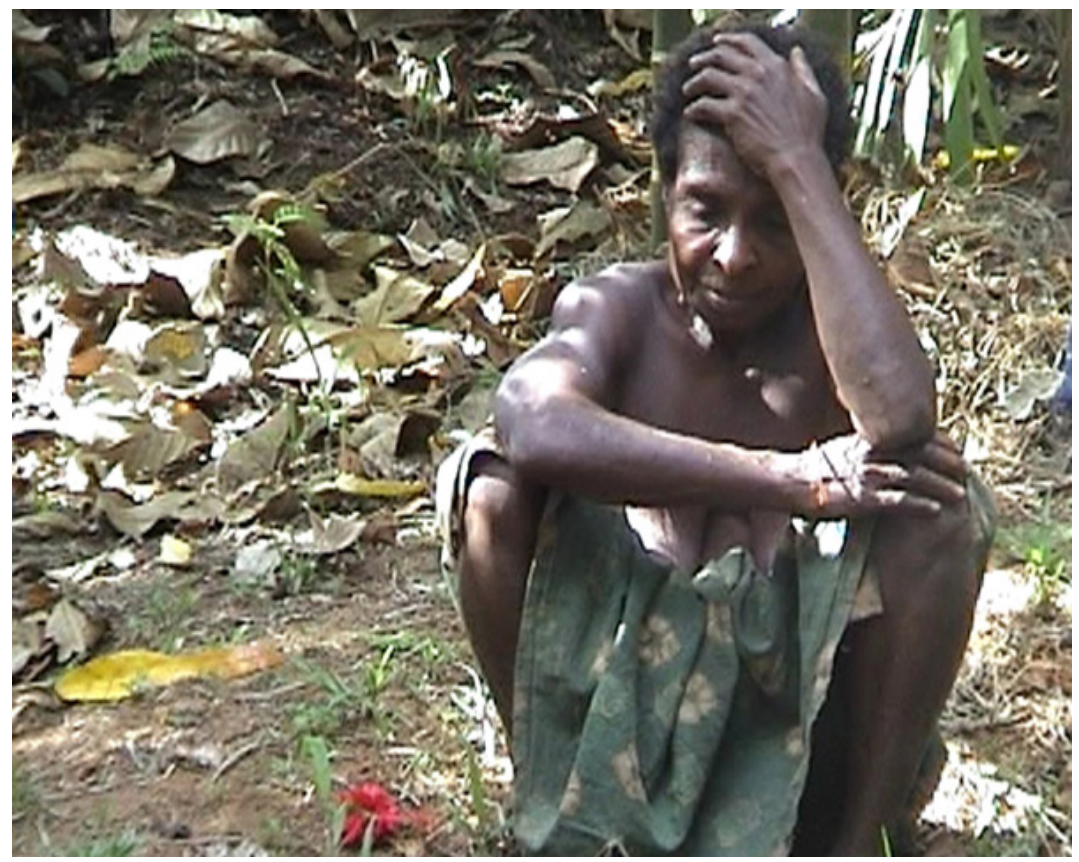

Figure 4 Kununda weeping for her dog Mek

Photo: D. Hoenigman 
In her lament, Kununda expresses her grievance that her sons would not help her reciprocate for the now deceased dog that had been given to her by people from Konmei village. By failing to do so they prevented her from being a moral person and fulfilling her obligation. She emphasises that she is a moral person by saying that she would never hide her dog's kill and eat it secretly by herself. This kind of behaviour is highly condemned in Awiakay society and is considered very antisocial, as one is expected to share all the food they find with others. While they all benefited from the dog, her sons did not pay attention to Kununda's worries, as she was indebted to people from another village. In that neglect, they did wrong to her. Moreover, by hitting the dog (probably chasing him away while they were eating his kill) they did wrong to Mek, which was again directed at Kununda, as dogs are their owners' extensions.

Following the taboo against uttering deceased persons' names, in her weeping, Kununda never mentions Mek's name, but always calls it just 'dog'. After she stopped crying, Kununda kept complaining about how she and Mek had been mistreated by her sons, while her sister Pambain waited to carry the dead dog away. Kununda stayed in the house, but her melodic crying could still be heard while we were burying the dog.

The reader who has access to the Internet is now invited to go to the following link and watch a film excerpt, which is a recording of the event discussed above.

\section{See film 1 [5:35] Kununda's Lament by Darja Hoenigman ${ }^{15}$}

In Awiakay society a lament is not just an expression of grief and loss. It is also a means to bring out grievances about disorders in social relations: about other people's wrongdoings towards the deceased or, even more often, towards the lamenter him/herself. ${ }^{16}$ This practice is in accord with the Awiakay conviction that any grievances, resentments or worries should be let out, lest they lead to sickness - and death.

\section{Conclusion}

For the Duna and the Awiakay, then, laments are more than the expression of an individual person's grief in song. Laments locate the deceased within their mortal life, and articulate the deceased's relationships with their community

15 View associated media files via the ANU E Press website <http://epress.anu.edu.au/titles/humanitiesresearch-journal-series/volume-xix-no-3-2013>

16 The Duna lament form khene ipakana yakaya has also been used as a platform to complain of unsatisfactory domestic relations. In one particular case the repetitive textual style and word substitution format allowed Kipu, on an occasion, to list her husband and all her children in turn and complain of them each causing her headaches with their unsatisfactory behaviour. See Gillespie, Kirsty 2010, 'Giving women a voice: Christian songs and female expression at Kopiago, Papua New Guinea', Perfect Beat, vol. 11, no. 1, pp. 7-24, at pp. 15-16. 
and the roles they have played within that community. Thus, laments present the deceased - as well as the lamenter - not only as individuals, but also as relational entities. In so many ways then, laments are a 'shared experience', as Steven Feld holds for Kaluli song. ${ }^{17}$ Even as the deceased has left the mortal world, he/she continues to embody those relationships for those who are left behind.

17 Feld, Sound and Sentiment, p. 34; Feld, Steven 1987, ‘Dialogic editing: interpreting how Kaluli read sound and sentiment', Cultural Anthropology, vol. 2, no. 2, pp. 190-210, at p. 200. 